\title{
Study on Aesthetic Institution and Contemporary Aesthetic Criticism Dimension*
}

\begin{abstract}
XIANG Li
Yunnan University, Kunming, China

More attentions have been paid to the relationship between institution and aesthetics/art, as the core issue of contemporary aesthetics in the background of linguistic turn and anthropological turn of contemporary aesthetics. The contemporary transformation of aesthetic/art institution is triggered by the multiple contradictions and complications among aesthetic/art and institution. One critical way to enable contemporary aesthetics to exceed traditional paradigm of aesthetics and art criticism is to rethink the institutional dimension of the aesthetic and art. On the basis of ethnographic exploration of contemporary social situation, contemporary mechanism of art circle and all kinds of critical consciousnesses, the criticism of aesthetic institution has motivated multiple dimensions of contemporary aesthetic criticism. According to the contemporary circumstances, the criticism dimension of contemporary aesthetics mainly focuses on the following several themes: the aestheticization of everyday life; the deconstruction and reconstruction of the boundary of beauty; art by metamorphosis: the formulation mode of art; criticism of aesthetic capitalism: distinction and cross boundary; political potential of the art of volneralble groups: the power of aesthetic resistance; aesthetic institution criticism and liberal government. On the basis of the above, the ultimate respect to "beauty" by contemporary aesthetics is to start two dimensions, i.e., poetics and politics of contemporary aesthetics eventually by clarifying the relationship between the aesthetic and art and politics/power, and practicing some transcendence by taking the aesthetic as one special institutional form.
\end{abstract}

Keywords: aesthetic institution, contemporary aesthetics, criticism

More attentions have been paid to the relationship between institution and aesthetics/art, as the core issue of contemporary aesthetics in the background of linguistic turn and anthropological turn of contemporary aesthetics. The discussion of this issue in the academic circle at present includes the theory of "Art Circles" of Arthur Danto, “Artistic Custom” of George Dickie, "the theory of Field” of Pierre Bourdieu, "the Institutional Theory of Art/Literature" of Peter Bürger, contemporary discussion on art circle by H. S. Becker and "Institutional Theory of Art" of Jacques Rancière, all of which have reflected different domains of discourse and emphasis but they all cling to recessive non-appearance aspects of artwork as always ignored in traditional aesthetics. According to the theories above, works are investigated by putting them in their institutional background and interpretation on how people's ideas and behaviors of "beauty" and "arts" are constructed by such institutional factors as aesthetic ideology, art knowledge, conventional concept, politics, power and economy. All these discussions manifest that the aesthetic and art are no longer pure consciousness and

\footnotetext{
* Acknowledgements: This paper was sponsored by China National Social Science Foundation "Research on the Fundamental Problems of the Contemporary Aesthetics and Criticism Patterns" (15ZDB023).

XIANG Li is a professor in School of Humanities in Yunnan University, China.
} 
conception or linguistic form but they imply multiple contradictions and complications among knowledge, structure, desire and power. The contemporary transformation of aesthetic/art institution is triggered by the multiple contradictions and complications among aesthetics/art and institution.

The proposal and study of "aesthetic institution" largely means activating the inherent tension and reconstitution dimension between institution and aesthetics/art on the basis of referring to and rethinking the relevant study achievements above by using the study idea and method of aesthetic anthropology ${ }^{1}$. Briefly speaking, aesthetic institution is somewhat construction and standard regarding "what beauty/art is" and "how to appreciate beauty/evaluate and perform art". The study of aesthetic institution lies in discussing, rethinking and criticizing a series of issues such as how these constructions and standards are formed, changed and their causes and essence. Therefore, "aesthetic institution" is not equivalent to "beauty" itself but a way to display and shield "beauty". "Aesthetic institution" therefore is related to "beauty" in term of this significance.

Different from traditional aesthetics, aesthetic institution is no longer focused on "beauty must be like this" but on how "beauty" is constructed, interpreted and acted. This key points on the aesthetic and art investigation in this study lie in special aesthetic sensation and social cultural mechanism formed and regenerated through activities and lays emphasis on the "being constructed" and "being able to construct" of beauty so as to transfer the study of aesthetics from imaginative spiritual activities to practical activities acting on real lives in society. The discussion regarding aesthetic institution in the current study of aesthetic anthropology is expanded through thinking and interpreting such issues as arts circle/network/framework, relationship of aesthetics and politics/power, deformation and arts and aesthetic locus. In general, to bring forth and keep discussing aesthetic institution means dissecting and rethinking cultural context of academic circle, which means context study becomes increasingly critical for the significance of aesthetics study. It has critical theoretical value and practical significance in discussing the basic issues of contemporary aesthetics and exploring contemporary criticism formation.

One critical way to enable contemporary aesthetics to exceed traditional paradigm of aesthetics and art criticism is to rethink the institutional dimension of aesthetic and art. On the basis of ethnographic exploration of contemporary social situation, contemporary mechanism of art circle and all kinds of critical consciousnesses, the criticism of aesthetic institution has motivated multiple dimensions of contemporary aesthetic criticism. According to the contemporary circumstances, the criticism dimension of contemporary aesthetics mainly focuses on the following several themes:

1. The aestheticization of everyday life: the deconstruction and reconstruction of the boundary of beauty. Aesthetic institution is reconstructed by daily life, which is a basic fact faced by contemporary aesthetics and

\footnotetext{
${ }^{1}$ As one kind of emerging conscious interdisciplinary subject, aesthetic anthropology has been gradually formed and developed in foreign countries since 1970s. In Western countries, research groups such as Anthropological Aesthetics (Diffey, 1984), the Anthropology of Aesthetics (Flores, 1985; Coote, 1989), Aesthetic Anthropology (Maquet, 1979) have been formed regarding the cross study of aesthetics and anthropology. Works regarding new study arts and aesthetic direction expanded based on anthropology study method and study of such issues as aesthetic preference of non-Western groups have been formed, triggering a series of frontier topics regarding the cross study of anthropology and aesthetics. Aesthetic anthropology tries to clarify the complicated relationship between aesthetic phenomenon and other cultural phenomenon, which entails the study of cultural facts that are still alive today, discussion of different manifestations, features and functions of "beauty" in different cultural contexts and the deep cause that leads to the complexity and specialty of "beauty". According to the study theory, it is highlighted that the study of "different culture" or "others" should be combined with the idea on contemporary cultural crisis so as to establish aesthetic cultural idea that is more balanced. The inter-discipline property of aesthetic anthropology and the sharp insight cultivated constantly provide special review perspective and broad experience interpretation space for discussing how "beauty" exists as one kind that is constructed and able to be constructed.
} 
contains all complexities of contemporary aesthetics: on one hand, it brings the renaissance of aesthetics and on the other hand, it means lost after the boundary fades away; in other words, aesthetics and art release the due vitality while crashing in the rigid boundary of traditional art circle. Subsequently, the aesthetic and art are embezzled, integrated and assimilated by other ideology subtly. The aesthetic enlightenment of art even degenerates as one kind of untrue promise and tiresome topic of conversation. This is actually a fact that can not be avoided for the criticism of contemporary aesthetics.

2. Art by metamorphosis: the formulation mode of art. As pointed out by one Belgian American anthropologist Jacques Maquet, in Western society, art is mainly formed through two ways: "art by destination" and "art by metamorphosis". Among which, the former is the art "with art for art" to be looked at according to the expectation and it is assumed to represent human's aesthetic pursuit with the highest form. Differently, the latter one is the product of Western aesthetic ideology and the "art formed by the people who are far away from carver and observer historically and geologically along the history"2. On the basis of above, "metamorphosis" is actually the art fact regarding "how one thing can become work of art" through the interpretation of ideology; however, such "metamorphosis" needs reviewing and this is where discourse hegemony of art and gentle violence lie. Therefore, the critical way to discuss and explore contemporary aesthetics and art autonomy space is to interpret the construction principle of "absorption" and "rejection" institution and reflect the identity politics included in the special relationship among things, humans and social order by taking the art exhibition of such organizations as contemporary museums, museums of arts, art galleries and galleries as an example.

3. Criticism of aesthetic capitalism: distinction and cross boundary. In the era of contemporary aesthetic capitalism, the aesthetic and art have become one of the main engines that promote social development. The battle of aesthetics has become the core for economic war in industrial civilization society. Under such a special context, it would be contemporary and challenging to discuss how the taste of aesthetic preference aggregation morphology is formed, what relationship and fight for word leadership between capital and power are contained in the context of such kind of aesthetic grade order and how we dig taste "irregularity". This study is based on one fact: to interpret "taste" of the aesthetic and art is shared by all humans rather than born for one distinctive scope and it has become the social institution deeply rooted in human's inner heart.

The distinction of taste has been extraordinarily interpreted in Bourdieu's book called Distinction. Bourdieu pointed out one fact that was uneasy to be perceived by humans: "beauty" had become one kind of special representation and extension mode of social order construction and logic of taxonomy. People's understandings and evaluation on art are generally restricted by the code and theme of some in-depth classification institution as well as some special historical imagination and political unconsciousness. Such kind of modern logic of taxonomy plays a quasi-religious role in defining sacred and worldly ones. "Beauty" is classified into all grades consequentially and the distributed role is finished in the position designated. Accordingly, in a majority of works of Bourdieu, Bourdieu insisted on the uniformity of habit, which means that inside one level (layer), the cultural taste based on certain social origin and educational mechanism shape and the cultural habit based on lifestyle are uniform since they have almost the same formation mechanism, which leads to different aesthetic preferences and cultural choices of the members in this level (layer) and those in other levels (layers). Therefore, the aesthetic taste generated by the aesthetic and art are transformed into distinction property accordingly. However, Tony Bennett declared that such distinction was not that clear as

2 Jacques Maquet (August 1979), “Art by Metamorphosis”, African Arts, 12(4), 33. 
said by Bourdieu through a number of social investigations and data. What is more, Tony Bennett also pointed out that idea of Bourdieu on this issue might hinder human from fully understanding some complicated and contradictory modes of actions and even might deprive the political right and capacity of the working class and become one strategy deeply rooted in Western aesthetic word traditions. On the basis of the above, Tony Bennett stressed the importance of habit in free governance. Tony Bennett believed that the change of habit is actually a critical mark of social progress and it could bring true power for aesthetic revolution by breaking rigid boundaries. This is actually a revolutionary topic. It has become a very critical way for us to investigate aesthetic capitalism criticism contemporarily from two perspectives of distinguishing society by taste and taste "irregularity".

4. Political potential of the art of volnerable groups: the power of aesthetic resistance The contemporary anthropological criticism is discussed by focusing on such issues as "power", "multiculturalism" and "marginal words" from two dimensions, including "ideology criticism” and "daily life criticism”. In particular, "ideology criticism”3 aims at "eliminating mystification", which means revealing the substantial basis of ideology and rigorous operation mechanism. "Daily life criticism" ${ }^{4}$ is actually a more experimental study which subtly transforms ideology into daily life; that is to say, it discusses the ways of people to adapt to and resist ideology strategies in daily lives. In contemporary society, the two kinds of criticism types are actually in concatenation, which reflects bidirectional dimensions of deconstruction and construction; anthropological criticism is involved in contemporary aesthetics by mainly discussing the following two issues: on one hand, it reveals the post-colonial treatment and inquiry of non-Western art in the construction and maintenance of Western aesthetic institution and the stimulation of political potential of vulnerable group art is established based on such kind of aesthetic institution criticism. On the other hand, it interprets the special mode of expression and value significance of art of ethnic minorities, marginal population and vulnerable group, explore the idea and passion behind them to enrich and develop the study on post-colonial criticism and "words of the vulnerable" theory and to actively discuss the strength of social reform contained by these arts and practice mechanism so as to bring "silence" another new mode of expression in contemporary times.

As for the art study of anthropology, for instance, The Savage Hits Back of Julius E. Lips (1937) described how the artists and handicraftsmen of non-Western society interpreted the image of white people in their drawings and sculptures with both pictures and excellent essays. They used diversified ways of representation in ironic cartoons which were seemingly unromantic and amusing. This is the criticism of colonialism in early

\footnotetext{
${ }^{3}$ Ideology criticism is one critical dimension for Marxist Criticism. For instance, one great contribution made by Althusser School was about the special distinction and analysis on ideology as well as the division of national power control organization into state apparatus and ideology state apparatus. The former include the functions of government, administrative departments, troop, policeman, court and prison through violence while the latter include the functions of religion, education, family, law, politics, trade union and cultural organization through ideology. Although ideology state apparatus does not work through violence externally, its coerciveness is furtive and is the pre-set form and dominance of state apparatus. Therefore, the furtive and complicated function mechanism and function can not be ignored.

${ }^{4}$ Daily life owns dual attributes and self-reconstruction possibility: on one hand, daily life exists as the object criticized, such as general conventional mechanical way adopted by people gradually in daily life according to Hegal's theory, Marx's theory that daily life is the place where commodity fetishism and dissimilation labor happen, Weber's metaphor of daily life as an "iron cage" governed by tools rationally and Heidegger's idea of regarding daily status as one kind of shielded status; on the other hand, daily life also implies the potential of denying and overturning alienation phenomenon, just as interpreted by Marx, Lukacs Gyorgy, Antonio Gramsci, Henry Lefebvre and Agnes Heller as well as representatives of British culture studies such as Raymond Williams, Richard Hoggart and John Fiske in daily life criticism ideas. In summary, daily life probably becomes the subject of daily life criticism.
} 
stage. Besides ${ }^{5}$, Raymond Firth also pointed out that it was no longer novel by exerting the role of political speed via art media. Along the history, art was intentionally used to enable people to understand and transfer social order. Firth believed that the consequence caused by "political art" is uneasy to evaluate, such as realism of Soviet Union or Chinese wall paintings on the struggle of farmers. ${ }^{6}$ The significance of these studies lies in bringing powerful interpretation to the formation and significance of special type of art by studying the special cultural background; what is more, the aesthetic resistance power contained in art as explored in this process brings critical theoretical value and practice significance for us to study contemporary aesthetic issues such as aesthetic resistance and aesthetic restoration.

5. Aesthetic institution criticism and Liberal government. In the long process of historical development, the aesthetic and art play a special role in practice governance. In other words, governance is one kind of art subtly meditating between aesthetics and politics. The involvement of aesthetics in society is actually a subtle governance strategy and in particular in aesthetic capitalism era, the factor of aesthetics and culture has become one of the main engines that promote social development. Such kind of special governance form shall entail more emphasis and study of ours. What is worth mentioning is that the aesthetic and art can not simply and individually realize such function by itself but work by mixing and working together with different kinds of institutional factors and mechanisms. This kind of special institution form is called aesthetic institution.

"Criticism" is actually about "distinction" and "demarcation". The task of criticism is to make thing become itself. Therefore, the criticism of aesthetic institution is to analyze how beauty is shielded during the process of being constructed and how to display beauty faithfully and its free regeneration on the basis of fully displaying itself. In the contemporary aesthetic field of vision, the liberal governance means the aesthetic and art can exert an initiative role in society and public field while existing and reproducing in contemporary circumstance based on their own rule and features. It is undoubted that such discussion is actually beneficial practice of how to make criticism involve in art, theory and reality. Aesthetic institution criticism is certainly where the inner core of aesthetic criticism lies. The real aesthetic institution can be established after aesthetic institution criticism and become the solid foundation for liberal governance space of the aesthetic and art, which is just the ultimate goal of contemporary aesthetic criticism.

Eagleton ever brought us a question which seemed conventional but set us thinking: "what is the point of literature theory"? To him, it is unnecessary to worry about it in academic myth of "pure" literature theory, and somebody will even think that any idea or behavior of associating literature with politics would imply necessary strong disapproval. As for this issue, Eagleton pointed out "all criticisms are somehow political". "Politics" to him meant a way of organizing his own social life organizations and the power relationship contained by such way. Therefore, Eagleton stressed that it was not "bringing politics into literature theory" but "politics lies there at the very beginning". ${ }^{7}$ In fact, politics and the power it contains penetrate in the classified framework of society with its private operation mechanism and the aesthetic and art also lie here deeply and subtly describe social relationship as one kind of special ideology. On the basis of the above, the ultimate respect to "beauty" by contemporary aesthetics is to start two dimensions, i.e., poetics and politics of

\footnotetext{
${ }^{5}$ See Jeremy Coote and Anthony Shelton (Eds.), Anthropology, Art, and Aesthetics, 1992, pp. 21-22.

${ }^{6}$ Raymond Firth, Art and Anthropology, in Jeremy Coote and Anthony Shelton (Eds.), Anthropology, Art, and Aesthetics, Oxford: Clarendon Press, 1992, pp. 35-36.

7 See Terre Eagleton: Western Literature Theory in the $21^{\text {st }}$ Century, translated by Wu Xiaoming, 2007, pp. 196-213.
} 
contemporary aesthetics eventually by clarifying the relationship between the aesthetic and art and politics/power, and practicing some transcendence by taking the aesthetic as one special institutional form.

\section{References}

Jacques Maquet. (August 1979). “Art by Metamorphosis”. African Arts, 12(4), 33.

Jeremy Coote \& Anthony Shelton. (1992). (Eds.). Anthropology, Art, and Aesthetics. Oxford: Clarendon Press.

Terre Eagleton. (2007). Western Literature Theory in the $21^{\text {st }}$ Century. (Wu Xiaoming, Trans.). Beijing: Peking University Press. 